\title{
Laptop Versus Longhand Note Taking in a Professional Doctorate Course: Student Performance, Attitudes, and Behaviors
}

Shane P. Desselle, PhD; Patricia A. Shane, PhD

Touro University California, Vallejo, California

\begin{abstract}
Objective: To determine the relationship between longhand note taking versus laptop note taking on pharmacy students' examination performance and identify differences in attitudes and behaviors as it relates to the note taking process.

Methods: A small group of students consented voluntarily to take longhand notes, doing away with their laptops during portions of the course administered by study investigators. Analyses were conducted on block examination performance, with each student's score on the first examination serving as a performance benchmark to assess change. Laptop and longhand note takers completed a survey regarding various aspects of their note taking attitudes and behaviors, and also included open text comments to capture qualitative experiential data.

Results: Based upon a relatively small number of participants in the longhand cohort ( $n=11)$, the differences between the groups on subsequent examinations was approximately 3.5 percentage points in favor of the longhand note-takers. There were significant differences observed between the two groups on several survey items, with longhand note takers less likely to be distracted in class and more likely to agree that other students ask to review their notes due to the quality of those notes.

Conclusions: Longhand note taking might facilitate more accurate recall or retrieval in test situations, thus producing improved test scores for certain types of students in certain types of courses; however additional research is needed. Faculty may consider whether modifying students' classroom note taking practices may contribute to an improved learning experience.
\end{abstract}

Keywords: notetaking; laptop notetaking; longhand notetaking; paper notetaking; student performance

\section{Introduction}

Technology continues to be incorporated more frequently into student pedagogy. Many students use laptops to take notes during lecture components of courses. Recent reports have called to question the wisdom of such ubiquitous use of laptops. A story in the New York Times described the latest concerns regarding use of laptops in the classroom (and elsewhere), suggesting that their use might be less than optimal for learning and retention of materials. ${ }^{1}$ This New York Times article referenced several studies described subsequently in this paper and was disseminated, shared, and discussed widely on social media. To that end, the issue of laptop use for note taking has garnered a considerable amount of attention.

There are several issues surrounding laptop note taking in the classroom that merit concern. One is the intrusion of distractions, e.g., competing content and the temptation to task shift. The availability of the Internet, various software, games and other readily accessible electronic technologies provide for an easy distraction ${ }^{2}$ with neighbors' open laptops on social media and other pages. ${ }^{3}$ Additionally, where a student could previously chat with one's neighbor, that ability is now extended to persons across or even outside the classroom. ${ }^{4}$ Sana, Weston, and Cepeda conducted two experiments. In the first, a group of students were

Corresponding author: Shane P. Desselle, PhD Touro University California, Vallejo, California Email: sdesselle68@gmail.com given additional tasks thought to mimic "typical" online searching and recreational use by students. ${ }^{5}$ A second experiment observed students situated adjacent to those given such tasks. In both experiments, test subjects performed significantly lower on a subsequent examination than did control subjects. They reported that multitasking, as is often undertaken during laptop note taking, can be a distraction to both users and fellow students. Similarly, Hembrooke and Gay undertook an evaluation of two groups of students. One group was allowed to engage in browsing versus the other group who kept their laptops closed. Students in the laptop group demonstrated lower recall of lecture content. ${ }^{6}$

Fiorella and Mayer found that students taking notes by hand were more likely to use spatial strategies, such as maps and drawings, to accompany outlines and running text, which improved learning outcomes. 7 In addition, students using a computer-based notetaking typed words without adding self-made diagrams, suggesting that the absence of spatial strategy use could be problematic. Mitchell and Zheng ${ }^{8}$ conducted a content analysis of notes and found higher quality of those taken by longhand versus laptops. Olive and Barbier observed the use of longhand note taking to be associated with greater metacognitive study strategy use by students well after class. ${ }^{9}$

In what has become widely regarded as the seminal study in this arena, Mueller and Oppenheimer conducted three discrete experiments on laptop note taking. ${ }^{10}$ In the first, they presented a series of TED talk films to students who were instructed to use their usual classroom note taking strategy. The participants then responded to both factual/recall and application questions about 
the films. The test scores of longhand note takers exceeded those of laptop note takers, even while participants using laptops were found to take lengthier "transcription-like" notes during the films. Mueller and Oppenheimer opined that the decrease in retention appeared to be due to verbatim transcription. In the second experiment, they instructed a new group of laptop note takers to type without transcribing the lecture verbatim and to take the notes in their own words. These participants also watched a film and took a test. The researchers found that their request for nonverbatim note taking was largely ignored by the students. In the third experiment, the investigators confronted the possibility that the additional word count of notes produced by laptop note takers would be beneficial later on when studying those notes. After a brief lecture where students were given the option to take notes in the style they preferred, those same students returned a week later and were given 10 minutes to study those notes prior to a quiz wherein the longhand note takers outperformed the laptop note takers on factual and conceptual questions. Mueller and Oppenheimer suggested that "although more notes are beneficial, at least to a point, if the notes are taken indiscriminately or by mindlessly transcribing content as is more likely the case on a laptop than when notes are taken longhand, the benefit disappears."10 (pg. 143)

It has been suggested that note takers would be well served if they become cognizant of the type, context, and speed of material to which they are listening and recording notes, as differences in these areas can impact effective note taking and subsequent learning. ${ }^{11}$ Mueller and Oppenheimer have since provided helpful strategies for note taking in different settings, including the classroom, boardroom, hospital room, and courtroom, with specific attention accorded to the technologies employed in various situations while acknowledging that the research on note taking in some areas remains inconclusive. ${ }^{12}$

The evidence for use of longhand note taking is not unequivocal. In a wide-ranging series of experiments evaluating student performance during class and retention of material, Eason maintained that the only significant finding was that student note taking, regardless of method, leads to better information retention, versus no note taking at all. ${ }^{13}$ Carraher found improved academic self-efficacy with laptop use, as students suggested that with laptops, writing becomes easier, their capacity to conduct research is enhanced, and their real-time engagement is boosted. ${ }^{14}$ Quade, whose study was conducted over two decades ago, found laptop note taking to be at least equal if not superior in some areas (e.g., recall scores) when the instruction itself is delivered online, a delivery format that is becoming more commonplace. ${ }^{15}$

The aforementioned studies were conducted in undergraduate courses, primarily in the liberal arts. The investigators are unaware of similar research conducted in a professional degree course. Professional degree courses are typically more challenging, and given the integration of various concepts might offer a unique challenge and perspective to evaluate the note-taking phenomenon. Moreover, the aforementioned studies often employed a briefer time period (e,g. one class session) examining recall the ensuing week. No studies examined test performance on more than one examination, and no experiments were accompanied by students' self-assessment of note taking strategies, including the effectiveness of those strategies, along with other attitudes and experiences that govern note taking. The literature, while consisting of experimental designs with randomization, were largely conducted outside the normal activities in a course; or in other words, did not involve situations where course grades hung in the balance and did not an employ an initial timeframe where students used a laptop and had to adjust to taking longhand notes. As such, the objectives of this study were to determine the effect of longhand note taking versus laptop note taking on pharmacy students' examination performance and to identify differences in their attitudes and behaviors as it relates to the note taking process.

\section{Methods \\ Setting/Course Design}

The pharmacy health systems course (PRMC 603) at Touro University is offered by faculty in the social, behavioral, and administrative sciences department to professional year 1 (P1) Doctor of Pharmacy (Pharm D) students and follows a block schedule, with 17, three-hour block sessions, in addition to examinations. The course incorporates group discussion exercises, a series of motivational interviewing training sessions employing standardized patients, and use of a social media platform (Twitter) to broaden course materials/topics and stimulate reflection. The two principal instructors employ a variety of interactive student exercises throughout the course, but still rely much on traditional lecture to convey material in this introductory course, which addresses a broad array of health care delivery topics at the systems level, such as health literacy, health disparities, medical access for the indigent, private insurance, epidemiology, and medication safety.

Approximately $75 \%$ of points available for students in the course are derived from three non-cumulative block examinations (25\% each). The remainder of the course grade is determined through reflection papers, structured group discussion exercises, role play, and active participation during class. As such, while there are a number of course activities to engage students, the majority of students' course grade is determined from their performance on the block examinations, thus making note taking during lectures critically important, even while the sessions are videotaped for asynchronous viewing. Course faculty noticed that the majority of students in recent years had been taking notes with laptops and anecdotally observed many students attempting to take notes verbatim, with some students occasionally having multiple windows open for emailing, social media, online shopping, and other activities. This and recent evidence questioning the effectiveness of note taking using laptop computers prompted two of the principal instructors (health systems and communications) to conduct an experiment offering students the 
opportunity to participate in the study's intervention group by taking longhand notes.

\section{Study Intervention}

The study protocol was approved by the University's Institutional Review Board and exempt from full review. Immediately following the Block A examination, a message was sent on the course Blackboard learning management site describing the study and calling for students with potential interest in the intervention (longhand note taking) arm to meet with the investigators prior to the next course session. Twelve students attended the session. The goals and general procedures of the study were explained, and prospective participants were offered consent. Eleven of the 12 opted to do so. The consent acknowledged their participation and afforded them the opportunity to drop out of the study at any time. Participation in the study required that students put away their laptop during any lecture by either of the two principal investigators and take notes only by hand (other devices like phones and tablets were not precluded). Students in the longhand note-taking group were instructed that they could use laptops or whichever note taking method they chose when another instructor was lecturing and that this study had no bearing or any dictates regarding their note taking in other courses. The study design purposefully allowed students to volunteer for an intervention likely foreign to them that would occur in a naturalistic environment with real course grades at stake. Therefore, this intervention had real meaning, without raising ethical issues of students being compelled to participate in any activity that could jeopardize their academic standing.

Performance of note takers (longhand versus laptop) was ascertained using percentage scores on the block examinations. All block examinations were comprised of 50 equally weighted multiple-choice questions. Material and questions from the principal investigators combined consistently accounted for approximately $70 \%$ of the course throughout Blocks A, B, and C. The examinations were non-cumulative, and each covered different, albeit related, materials in health systems and professional communication. Serving as the pre-intervention "control," the Block A exam scores were recalculated for the purposes of this study to include questions only from the two principal investigators. Likewise, the Block B and Block C exam scores were calculated as percentage scores from questions and material covered only by the principal investigators. Exam performance differences were calculated by subtracting the Block $B$ percentage scores from Block A percentage scores; also subtracting Block $C$ percentage scores from Block $A$; and then finally subtracting the average percentage score of Block $B$ and Block $\mathrm{C}$ from the Block $\mathrm{A}$ score for each student.

The entire class of students was invited to complete one of two forms (longhand version and laptop version) of a selfadministered questionnaire survey involving different aspects of their note taking beliefs and experiences. Survey items were derived from the broader literature on note taking, in addition to papers focusing on laptop note taking, specifically. A number of references cited throughout this paper provided information that led to the creation of items. The majority of items were generated directly from Eason and Kay ${ }^{13}$ and Kay and Lauricelli ${ }^{17}$. The rationale for the items chosen was to identify potential ramifications of note taking, note-taking attitudes, along with potential antecedents or rationales behind how and why students undertake certain note taking behaviors. For example, various papers discussed the possibility of certain note takers beginning the decoding process while taking notes, others use laptops to enhance the visual experience of the lecture, other considerations discussed in the literature include various abilities to and ramifications of keeping pace with lecture and having good handwriting speed, fluency in English language comprehension, the quality of notes taken, and the usefulness of notes when preparing for examinations. Students were given the opportunity to complete this survey during an early class session in the subsequent spring semester offered by the social, behavioral, and administrative sciences department (a management course). The main component of both versions was a list of 25 items measured on a 6-point, Likert-type scale ranging from 1 (Strongly Disagree) to 6 (Strongly Agree) with no 'neutral', 'not sure', or similar category. The use of such neutral scale points are questionable; specifically, it is argued that opinions on a specific aspect rather than the larger phenomenon are not neutral and that having such a category can disengage the survey-taker. ${ }^{18}$ There were a spectrum of items rather than being all positive or all negative, or purposively constructing a limited number that might require reverse-coding. ${ }^{19}$ There were also two open-ended, or qualitative questions. These asked respondents to share any comments about note taking and what they opined that faculty, staff, and/or administrators could do to promote effective note taking by students. The survey was administered and undertaken using paper copy and pen/pencil.

Students in the longhand note-taking group received the same 25 items described above and the same two open-ended questions. Additionally, this form of the survey contained 6 more items rated on the same 6-point, Likert-type scale. These items solicited the extent to which students in this group were able to adjust to taking notes by hand, whether they would recommend doing so for other students, and whether they will continue taking notes by hand in other courses. It also had one additional open-ended question soliciting any comments for having participated in the longhand note-taking group of the study.

Analysis of examination performance was undertaken using independent sample t-tests of percent scores between longhand and laptop note takers using SPSS, v. 19.0 (International Business Machines Corp , Armonk, NY). Additional t-tests were conducted on percent difference scores by subtracting for each group the average percentage score from Block $B$ from Block $A$, Block $C$ from Block $A$, and the average of Block $B$ and Block $C$ from Block $A$. Independent sample $t$ tests were conducted to determine significant differences in responses on survey items between longhand versus the laptop note takers. Frequency statistics on additional Likert-type items given only to the intervention group 
(longhand note takers) were calculated. Responses to the openended or qualitative questions were collected, and investigators took notice of recurring topics, but did not undertake a formal content analysis of these comments.

\section{Results}

There were 87 students enrolled in the course at its beginning and 86 who completed it, with one person (not in the longhand note taking group) who took a leave of absence during the semester. The investigators purposely did not request demographic data from the note-taking group nor from any student completing the survey. Some demographic characteristics of the entire class are provided in Table 1, as given by the University Office of Admissions, wherein demographic information relies primarily on student self-report. Nearly $2 / 3$ of the class was female. Most students had an undergraduate degree in any of several basic sciences (biology and chemistry being most prevalent), with 4 of them having a Master's degree, while fewer than $10 \%$ reported a degree in some other field, such as education or psychology. With regard to race/ethnicity, nearly $2 / 3$ of the class self-reported as Asian/Pacific Islander and nearly $1 / 4$ as White. These are the categories under which students self-report (in addition to Hawaiian and Native American). It should be noted there are a number of students in the class of Arab or Persian descent who likely self-report as White. Among the longhand note takers, 8 were female and 9 had a degree in basic sciences. Additionally, 5 were Asian/Pacific Islander, 5 were White, and 1was Hispanic.

\section{Student Examination Performance and Note taking Attitudes and Behaviors}

Table 2 provides the 3 block examination percent scores and the difference between the latter block examination scores and the initial (Block A) examination percent scores prior to the study intervention. There were no statistical differences between the longhand and laptop note takers across any of the examinations; however, some trends are worth noting. While their percent scores for Block A prior to the intervention were separated by just over $1 \%$, the differences between them on Block B and Block $C$ examination were approximately $5 \%$ and $4 \%$, respectively. Students in both groups generally performed better on the Block $B$ and Block $C$ examinations than on the Block $A$ examination. Longhand note takers averaged over $5 \%$ higher on the Block $B$ examination and nearly $12 \%$ higher on the Block $C$ examination than on the Block A examination; and laptop note takers averaged over $1 \%$ higher on the Block $B$ and over $9 \%$ higher on the Block $C$ examination. The average percentage score of Block $B$ and $C$ compared with Block A was $8.47 \%$ higher for longhand note takers, versus $5.17 \%$ higher for laptop note takers.

Table 3 provides the item statements and summary responses to the survey administered to the class regarding note taking preferences, study habits pursuant to their note taking, and other related attitudes and behaviors. Responses were acquired from 58 students, representing $67.4 \%$ of the class. Nine of the respondents were from the longhand cohort. The survey was administered during a subsequent course wherein attendance was not required.
Nearly every student in attendance in class on the day of survey administration voluntarily completed the survey.

For all students completing the survey (both cohorts), higher levels of agreement were obtained on items dealing with acquiring a preliminary understanding of course materials during lecture; attempts to process and understand material while taking notes; studying notes as an effective method to prepare for block examinations; having good English comprehension skills; keeping pace with note taking during lecture; and attention span limiting how much is understood during the lecture presentation. Lower levels of agreement were acquired on items suggesting that students had difficulty making sense of their notes once they began to read over them; other students looking at notes as a result of their being of such high quality; confidence in using first language (if not English); and getting distracted by classmates' keyboard typing.

Independent-sample $t$ tests revealed significant differences between the responses of longhand versus laptop note takers on several of the survey items, even with just 9 (of the 11 total) students in the intervention cohort having completed the survey. Longhand note takers versus laptop note takers were less likely to agree that they are distracted during lecture (item \#3, mean difference $=1.42, \mathrm{df}=1, \mathrm{p}<.01$ ), are tempted to get onto the internet and/or social media (item \#4, mean difference $=1.98$, df $=1, p<.01$ ); that color and visualization from the lecture slides helps them with learning (item \#19, mean difference $=1.39, \mathrm{df}=1$, $\mathrm{p}<.01)$; that color and visualization from the lecture slides makes the lecture more enjoyable (item \#20, mean difference $=1.32$, df $=1, p<.01$ ); that they use a laptop for other lectures (item \#21, mean difference $=1.45$, $d f=1 ; p<.01$ ); and that their attention span limits their understanding during lecture (item \#22, mean difference $=1.09 ; \mathrm{df}=1 ; \mathrm{p}<.05)$. They were more likely to agree that other students asked to look at their notes due to their high quality (item \#18, mean difference $=1.14$, df $=1 ; p<.05$ ). There were differences between the groups with $p$-values of less than 0.1 (i.e., 0.06-0.09) on item \#2 (preliminary understanding during class) (longhand note takers more likely to agree), \#7 (try to take as many notes as possible) (longhand note takers less likely to agree), item \#12 (identify key concepts during class) (longhand note takers more likely to agree), and item \#24 (grades not a good indicator of note-taking skills) (longhand note takers less likely to agree).

Table 4 provides selected, albeit a nearly comprehensive set of quotes from students in the laptop cohort. The comments were informally grouped into several topics. A number of students expressed either an evolving or a multi-faceted strategy for note taking. This coupled with verbal, anecdotal comments received intermittently throughout the course suggested students were learning that a professional curriculum (perhaps particularly this course) requires close listening, selective note taking, and an attempt to understand during lecture or very soon afterward, rather than typing all possible notes, verbatim. Some students were still seeking the proper strategy for taking notes and 
succeeding in the course. While one respondent (in the laptop cohort) suggested banning electronics, others provided additional suggestions including the sharing of notes by good note takers and even assigning federal work study students to take good notes for the rest of the class. Some students focused on the instructors improving various aspects of course delivery, most notably providing annotation, color-coding, and similar strategies to assist students with note taking, as they otherwise have difficulty keeping up or understanding what is important, or what will be on the examination. Finally, there were a group of students who provided justification as to why they use and might continue to use their laptops for note taking in class. A few extraneous comments were not included in this table, such as the difficulty of pharmacy school and there being too much material in all courses.

Table 5 provides ratings among the 9 longhand note takers completing the survey on the day of its dissemination. They were relatively neutral (average response near scale mid-point) about having good handwriting speed and whether taking longhand notes took some getting used to. They were in modest agreement (average response near agreement, but not strong agreement) that they have begun or will begin taking longhand notes in other courses and that students without good handwriting speed can still be effective longhand note takers. They were in more solid agreement (average response closer to strongly agree) with the idea of longhand note taking being better for some courses and instructors than with others and in regard to recommending that other students try this method of note taking.

Table 6 provides an exhaustive list of quotes from the longhand note takers completing the survey, including responses to the additional qualitative question seeking comments, in general. They affirmed the positive experience and claimed it to be particularly useful knowing that they can review videotaped lectures, that course performance was improved, and that they would encourage other students to give it a try, particularly using different sorts of pens or highlighters and taking into account their own learning style when actually executing the note taking, itself.

\section{Discussion}

This study was among the very few examining longhand versus laptop note taking over more than one examination period and found an approximately $3.5 \%$ greater improvement in examination scores for longhand note taking students on average, during two block examinations. Experiments in graduate or professional degree programs have been very rare. Additionally, this study examined various note taking attitudes and behaviors among students. The results of this study appear to corroborate much of the early evidence in evaluating this phenomenon, including some of the logic or rationale behind note taking behaviors and potential differences in student performance. Zahay and Kumar found that students typically overestimate their ability to split attention between social uses of technology and education uses, which suggests that students do not have the necessary information and experience to make informed decisions about use of mobile technology in the classroom. ${ }^{20}$ While their evaluations were conducted with younger students, current students in professional programs acclimated to technology might continue to overestimate their ability to maintain focus while multi-tasking. Longhand note takers in the current study were reportedly less likely to be distracted during lecture.

Additionally, students using laptop computers to take notes were more likely to agree that limitations in their attention could adversely impact understanding of course material. This might be due to increased distraction and temptation to engage in other activities, such as web browsing and social media. There might also be some contribution by the greater cognitive engagement involved in more selective note taking, rather than what is likely a tiresome task in attempting to write the greater volume of notes that is often associated with laptop note taking. Students taking longhand notes are purportedly more apt to begin the decoding process during lecture, thus facilitating their time management skills. ${ }^{2}$ This could be even more salient in longer class periods, such as courses taught in block schedules or other extended periods of time, not uncommon in professional degree programs.

This study also revealed some trends about students' attempts at learning related to note taking. Kay and Lauricella found that distractions in the classroom using laptops extend to similar distractions in their use outside the classroom, and that this interferes with the use of metacognitive study strategies. ${ }^{21}$ Students in both groups of the current study largely agreed that they try to understand the material during note taking, but perhaps somewhat less likely to read through the notes soon after class lecture.

Castillo-Manzano et al. found that students, in spite of their own fluency in the use of technology, bear additional concern, or worry about Internet connectivity issues in preparation for and during class. ${ }^{22}$ While the Likert-type items in the current study did not directly test for such a similar phenomenon, a few comments from longhand survey respondents indicated a reduction in worry.

Sandblom describes the need for students to be taught note teaking, even going so far as to suggest a course in this area. ${ }^{23}$ In her own course, she provides time for students to capture important concepts or definitions in their own words and imparts to students methods for conceptualizing their notes in more than one way, including guided self-reflection on improving the previous class session's note taking. Longhand note takers in the current study acknowledged that longhand note taking might be more effective in some types of courses than in others. This will likely depend not only on the subject matter, but the lecture styles and auxiliary visual aids employed by the instructor. In the current study, students were moderately satisfied with the accuracy and completeness of their notes; however, longhand note takers more strongly agreed that peers request to look at those notes due to higher quality.

Bohay et al. confirmed the notion of 'active note taking' even while not testing laptop versus longhand, specifically. ${ }^{24}$ In several 
manipulations, including the opportunity to take notes via longhand-only (no laptop cohort) and time accorded to review the notes and ask questions during class time, they found that active engagement appeared to have resulted in deeper learning. As such, while faculty consider various student learning styles in designing course delivery, they might suggest specific note taking and study strategies for students to optimize performance, engagement, and learning.

This is especially the case because technology and use of laptops will not simply "go away" or dissipate. Kay provided benefits and challenges to this reality. ${ }^{17}$ Benefits included enhanced collaboration among students, increased organization and efficiency, and the ability to address students' special needs, while challenges include the aforementioned distractions. Thus, instructors should be mindful of these benefits and challenges when confronting contemporary culture and providing the most optimal learning environment. As a greater number of students require reasonable accommodation, classroom laptops with new technologies could be that much more beneficial for students to enter, edit, and transfer text; magnify screen text; improve grammar and outlining; and develop other workplace skills. ${ }^{25}$

In promoting student autonomy and varied preferences, one might consider the results of an experiment by Aguilar-Roca et al, who zoned a biology course into laptop-permitted and laptop-free zones. ${ }^{26}$ Students in both zones who took notes with paper performed better than did students who took notes via laptop; however, there was no difference in performance between only the paper note takers across the two zones and no difference between only the laptop note takers across the two zones. Knowing contemporary students preferences in terms of laptop use, instructors might consider creation of such zones in classroom facilities where this can be made possible. Doing so, in addition to some verbal affirmation can signify to students that longhand note taking might be a preferable alternative even while not precluding laptop use.

\section{Study Strengths, Limitations, and Future Research}

Several limitations must be kept in mind when examining the results of this study. For one, the survey on student note taking was not piloted or assessed for validity. Second, while this was among the first studies to examine student performance over multiple examinations and concurrently take into account attitudes and preferences, the study took place in just one course in one semester. The course is unique in that it addresses health systems and communications in a professional pharmacy context; as such, the results could have been different with students outside of pharmacy or even other courses within a pharmacy curriculum. A notable strength of this study is that it took place during a course with real grades on the line, versus many experiments on content recall or quality of notes, with assessment outside normal course grading; yet at the same time, students were ethically accorded the opportunity to volunteer or drop out at any time. This precluded any attempt to power the study or attempt to obtain a specific number of intervention group students. The novelty of this approach resulted in only 11 students agreeing to participate, with none of those 11 dropping out. With only 11 participants in the study group, the results might have actually understated the potential benefits of longhand note taking. Even though it appeared as though longhand note takers complied with study protocol, their use of a laptop or other devices cannot be precluded. The investigators did not inquire about previous longhand note taking use among the 11 who volunteered; however, at 2-3 of them mentioned at least occasional use of longhand note taking previously, including during the course's Block A material, so there could have been some self-selection bias. Additionally, even while electing not to participate in the study, some laptop note takers indicated use of longhand, so some level of contamination is possible. Also, all course sessions are video and audio recorded. The ability of students to view the sessions at any time, for an unlimited amount of times, at a later date, might to some degree obviate the importance of note taking during class. This could have even further underestimated the true impact of longhand versus laptop note taking; however, the effects of note taking mechanism under the auspices of videotape ability remain unknown. The number of times students accessed the video recordings was not made available to the researchers. In addition, the study did not account for other aspects of student performance in the course, such as daily participation and work within group structured activities, which would have been difficult to account for and lacked a theoretical basis for examination.

The study employed multiple independent-sample $t$ tests, thus inflating alpha error; however, many significant differences on the survey were observed even at $p$ values below .01. The students self-selected into the study. It is possible that students who did so were leaning toward or more open to new types of course engagement and study strategies. Among the longhand note takers, 8 of the 11 were female and all but one was under the age of 30, statistics which would appear to resemble the remainder of course enrollees, though a formal comparison was not undertaken. For the data acquired on open-ended questions, a formal, content analysis or other more sophisticated approach to analyzing the data was not employed. There was no attempt here to induct theory or leverage this research specifically into the construction of themes. Rather, an attempt was made to simply to organize the comments from a small number of questions to stratify students' overriding thoughts on the issue. Unlike a content analysis providing a small number of example quotes from a much larger swath of semi-structured questions, a significant majority of quotes to structured survey questions are represented here. Students completed the survey approximately 4 weeks after completion of the course, so the possibility of recall bias among students in either group cannot be entirely precluded.

Additional research is needed on several fronts, including a greater number of students in a wider range of classes. Future research might ascertain the extent to which students might be able to employ various types of active note taking in various courses, or whether they might gravitate only to one particular 
style and have difficulty employing diverse strategies. Student learning styles should be investigated as a potential intervening variable. Nakayama observed that the learning styles of students and other characteristics could play a part in optimal note taking strategies, with potential differences among visual, kinesthetic and other types of learners in a strictly online environment. ${ }^{27}$ There is also additional research needed on the effects of English fluency, note taking speed, extent and type of use of visual imagery in slides, and other content delivery modalities, altogether.

\section{Conclusion}

This study examined test scores of a small group of students using longhand to take notes versus the remainder of course enrollees taking notes using a laptop computer, noting results that merit further investigation. Using a cross-sectional survey, the longhand note taking cohort was more likely to agree with there being fewer distractions and temptations, and having high-quality notes that other students ask to look at, while being more likely to disagree that their attention span limits their understanding. They also reported recommending that other students attempt more frequent use of longhand note taking, even while recognizing that this modality might not be suitable for all students in all types of courses. Faculty can consider these results in helping students devise optimal note taking strategies in their courses.

\section{References}

1. Dynarski S. Laptops are great. But not during a lecture or a meeting. New York Times. November, 22, 2017.

Available at:

https://www.nytimes.com/2017/11/22/business/laptop s-not-during-lecture-or-meeting.html. Accessed on April 26, 2018.

2. Awaad FA, Ayesh A, Awwad S. Are laptops distracting tools in the classrooms? Procedia Social and Behavioral Sciences. 2013;103(2):154-160.

3. Berry MJ, Westfall A. Dial D for distraction: The making and breaking of cell phone policies in the college classroom. College Teaching. 2015; 63(1):62-71.

4. Ravizza SM, Uitvlugt MG, Fenn KM. The negative effects of laptop internet use during class. Neuroscience Letters. 2017;63(1):44-49.

5. Sana F, Weston T, Cepeda NJ. Laptop multitasking hinders classroom learning for both users and nearby peers. Computers and Education. 2013;62(1):24-31.

6. Hembrooke H, Gay G. The effects of multitasking in the classroom. Journal of Computing in Higher Education. 2003;15(1):44-64.

7. Fiorella L, Mayer RE. Spontaneous spatial strategy use in learning from scientific text. Contemporary Educational Psychology. 2017;49(1):66-79.
8. Mitchell A, Zheng L. Examining longhand vs. laptop debate: Evidence from a replication. Replication Research-Proceedings from the Americas Conference on Information Systems, 2017. Available at: https://aisel.aisnet.org/amcis2017/Replication/Presenta tions/2/. Accessed on October 31, 2018.

9. Olive T, Barbier ML. Processing time and cognitive effort of longhand note taking when reading and summarizing a structured or linear text. Written Communication. 2017;34(4):224-246.

10. Mueller PA, Oppenheimer DM. The pen is mightier than the sword: Advantages of longhand over laptop note taking. Psychological Science. 2014;25(10):1159-1168.

11. M McGloin. What you miss when you take notes on your laptop. Harvard Business Review. July 31, 2015. Available at: https://hbr.org/2015/07/what-you-misswhen-you-take-notes-on-your-laptop. Accessed on May 1, 2018.

12. Mueller PA, Oppenheimer DM. Technology and note taking in the classroom, boardroom, hospital, and boardroom. Trends in Neuroscience Education. 2016;5(2):139-145.

13. Eason TE. Various methods of note taking and how they compare in terms of information retention. Master's Thesis. East Carolina University; 2017.

14. Carraher JM. Students' perceptions of academic selfefficacy and self-regulation while learning in a 1:1 laptop environment. Doctoral dissertation. University of Nebraska; 2014.

15. Quade AM. An assessment of retention and depth of processing associated with note taking using traditional pencil and paper and online notepad during computerdelivered instruction. Proceedings of Selected Research and Development Presentations at the 1996 National Convention of the Association for Educational Communications and Technology. Indianapolis, IN; 1996: pp. 559-570. Available at: https://eric.ed.gov/?id=ED397825. Accessed on May 11, 2018.

16. Kay RH, Lauricella S. Assessing laptop use in higher education: The laptop use scale. Journal of Computing in Higher Education. 2016;28(1):18-44.

17. Kay RH. Exploring the benefits and challenges of using laptop computers in higher education classrooms: A formative analysis. Canadian Journal of Learning and Technology. 2011;37(2):103-120.

18. Garland $R$. The mid-point on a rating scale: Is it desirable? Marketing Bulletin. 1991;2(1):66-70.

19. Robinson MA. Using multi-item scales for research and practice in human resources management. Human Resource Management. 2018;57(5):739-750.

20. Zahay D, Kumar A, Trimble C. Motivation and active learning to improve student performance. In: Creating Marketing Magic and Innovative Future Marketing Trends. Cambridge, MA: Springer; 2017: 1259-1263. 
21. Kay RH, Lauricella S. Investigating the benefits and challenges using laptop computers in higher education classrooms. Canadian Journal of Learning and Technology. 2014;40(1):1-25.

22. Castillo-Manzano JI, Castro-Nuño M, López-Valpuesta L, Sanz-Díaz MT, Yñiguez R. To take or not to take the laptop or tablet to classes, that is the question.

Computers in Human Behavior. 2017;68(4):326-333.

23. Sandblom N. Active-learning techniques for improving note taking skills. University of Calgary. Available at: http://hdl.handle.net/1880/50578. Accessed on May 3, 2018.

24. Bohay M, Blakely DP, Tamplin AK, Radvansky GA. Note Taking, review, memory, and comprehension. American Journal of Psychology. 2011;124(1):63-73.

25. Parette HP, Peterson-Karlan GR. Facilitating student achievement with assistive technology. Education and Training in Developmental Disabilities. 2007;42(5):387397.

26. Aguilar-Roca NM, Williams AE, O-Dowd DK. The impact of laptop-free zones on student performance and attitudes in large lectures. Computers and Education. 2012;59(11):1300-1308.

27. Nakayama M. Effectiveness of student note taking activities and characteristic of their learning performance in two types of online learning. International Journal of Distance Education. 2017;15(1):47-64. 
Table 1. Demographic Characteristics of Study Participants $(n=86)$

\begin{tabular}{|c|c|}
\hline Characteristic & $\mathrm{n}(\%)$ \\
\hline \multicolumn{2}{|l|}{ Gender } \\
\hline Male & $31(36.0)$ \\
\hline Female & $55(64.0)$ \\
\hline \multicolumn{2}{|l|}{ Race/ethnicity } \\
\hline Asian/Pacific Islander & $55(63.4)$ \\
\hline Black & $5(05.8)$ \\
\hline White & $19(22.1)$ \\
\hline Hispanic & $4(04.7)$ \\
\hline No response/unknown & $3(03.5)$ \\
\hline \multicolumn{2}{|l|}{ Undergraduate or other degree* } \\
\hline Basic/applied sciences & $78(91.5)$ \\
\hline Other & $8(08.5)$ \\
\hline
\end{tabular}

*Includes 4 students with Master's degrees in a sciences field.

Table 2. Examination Performance of Students in the Health Systems Course

\begin{tabular}{|c|c|c|}
\hline Examination & Scores* & Sig. ( $p$ value) \\
\hline \multicolumn{3}{|l|}{ Block A Examination } \\
\hline Longhand note takers & $75.28(9.41)$ & \multirow[t]{2}{*}{$p=.78$} \\
\hline Laptop note takers & $73.93(7.33)$ & \\
\hline \multicolumn{3}{|l|}{ Block B Examination } \\
\hline Longhand note takers & $80.29(8.88)$ & \multirow[t]{2}{*}{$p=.14$} \\
\hline Laptop note takers & $75.18(7.12)$ & \\
\hline \multicolumn{3}{|l|}{ Block C Examination } \\
\hline Longhand note takers & $87.21(8.59)$ & \multirow[t]{2}{*}{$p=.09$} \\
\hline Laptop note takers & $83.02(6.90)$ & \\
\hline \multicolumn{3}{|l|}{ Block B vs. Block A difference } \\
\hline Longhand note takers & $5.01(1.14)$ & \multirow[t]{2}{*}{$p=.08$} \\
\hline Laptop note takers & $1.25(0.97)$ & \\
\hline \multicolumn{3}{|l|}{ Block C vs. Block A difference } \\
\hline Longhand note takers & $11.93(1.87)$ & \multirow[t]{2}{*}{$p=.16$} \\
\hline Laptop note takers & $9.09(1.44)$ & \\
\hline \multicolumn{3}{|c|}{ Block $B$ and $C$ average vs. Block $A$ difference } \\
\hline Longhand note takers & $8.47(1.55)$ & \multirow[t]{2}{*}{$p=.11$} \\
\hline Laptop note takers & $5.17(1.02)$ & \\
\hline
\end{tabular}

* Mean (and standard deviation) percent scores based upon only those examination questions from the principal investigators. 
Table 3. Student Responses to Note Taking Survey Item Questions ( $\mathbf{n}=\mathbf{5 8}$ )

\begin{tabular}{|c|c|c|c|}
\hline Item statement & $\begin{array}{l}\text { Mean (SD) } \\
\text { Longhand }\end{array}$ & $\begin{array}{c}\text { Mean (SD) } \\
\text { Laptop }\end{array}$ & $\begin{array}{c}\text { Mean (SD) } \\
\text { All }\end{array}$ \\
\hline
\end{tabular}

1. I was able to keep pace with note taking during the lecture.

2. I was able to acquire at least a preliminary understanding of course materials while lecture was taking place.

3. I found myself getting easily distracted during course lecture.

4. It was tempting to get onto social media, the Internet, and/or other applications during course lecture.

5. I attempted to process and understand the material presented in lecture while I took notes.

6. I was able to be selective about the notes that I take in class during lecture.

7. I tried to take as many notes as possible (the professor's words, verbatim) during lecture.

8. I was able to visualize, create a mental picture, or think of examples during lecture that helped me process, or learn the material.

9. I typically read through my notes and tried to understand material presented in class soon (e.g., within a couple days) after that class session.

10. I was usually satisfied with the accuracy and completeness of the notes I had taken in class.

11. I had difficulty making sense of the notes when I began to read over them, later.

12. I was able to identify key concepts while I took notes during class.

13. Studying my notes was an effective method of preparing for Block exams.

14. Sometimes I got distracted by my classmates' keyboard typing or other activities they undertook on their computer during class.

15. I was able to recall my notes and the lecture the first time I read through them.

16. I have good English comprehension skills.

17. It was tiresome to take notes for an entire 3-hour class lecture, even when there are breaks or other activities built in.

18. Other students ask to look at my notes because they know my notes are of high quality.

19. In general, seeing the color and total visualization from having the slides on my laptop/device assists me with learning.

20. In general, seeing the color and total visualization from having the slides on my laptop/device makes the lecture session more enjoyable.

21. When there were lectures by faculty other than Drs. [redacted], I preferred not to take handwritten notes and used a laptop, instead.

22. In general, my attention span limits how much I understand during the lecture presentation.

23. I find that I am most confident using my first language

\begin{tabular}{|c|c|c|}
\hline $4.56(1.01)$ & $4.40(1.11)$ & 4.42 (1.09) \\
\hline $5.33(0.87)$ & $4.83(0.96)$ & $4.91(0.96)$ \\
\hline $2.33(1.23)$ & $3.75(1.30)$ & $3.53(1.38)^{* *}$ \\
\hline $2.00(1.00)$ & $3.98(1.38)$ & $3.67(1.50)^{* *}$ \\
\hline $4.89(0.93)$ & 4.55 (0.95) & $4.61(0.95)$ \\
\hline $4.56(1.13)$ & $4.29(1.34)$ & $4.33(1.30)$ \\
\hline $4.89(1.54)$ & $3.88(1.62)$ & $4.04(1.64)$ \\
\hline $3.89(1.27)$ & $4.02(1.21)$ & $4.00(1.21)$ \\
\hline $3.89(1.62)$ & 3.64 (1.61) & $3.68(1.60)$ \\
\hline $4.22(1.30)$ & 3.81 (1.39) & $3.88(1.38)$ \\
\hline 2.78 (1.09) & $2.45(1.27)$ & $2.50(1.24)$ \\
\hline $4.67(0.87)$ & $4.17(1.04)$ & $4.25(1.03)$ \\
\hline $4.89(1.27)$ & $4.67(1.27)$ & $4.71(1.26)$ \\
\hline $2.67(1.73)$ & $2.73(1.78)$ & $2.72(1.76)$ \\
\hline $4.11(1.45)$ & $3.75(1.26)$ & 3.81 (1.29) \\
\hline $5.00(0.87)$ & $4.88(1.91)$ & $4.89(1.14)$ \\
\hline 3.89 (1.87) & $3.85(1.53)$ & $3.86(1.59)$ \\
\hline $3.46(1.41)$ & $2.32(1.34)$ & $2.50(1.43)$ \\
\hline $3.11(0.78)$ & $4.50(1.30)$ & $4.27(1.33)^{* *}$ \\
\hline 3.25 (1.17) & $4.57(1.22)$ & $4.37(1.29)^{* *}$ \\
\hline $2.78(1.86)$ & $4.23(1.86)$ & $4.00(1.92)^{* *}$ \\
\hline 3.44 (1.51) & $4.53(1.32)$ & $4.36(1.39)^{*}$ \\
\hline
\end{tabular}


(if not English) and require time to translate some phrases and vocabulary.

24. My grades are not a very good indication of my note taking skills.

25. If I had to choose, I would prefer to share notes and study with others rather than rely solely on my own notes.

Response scale: 1 = Strongly Disagree; 2 = Disagree; 3 = Slightly disagree; 4 =Slightly agree; $5=$ Agree; $6=$ Strongly Agree. ${ }^{*}$ Significant at $p<.05 ;{ }^{* *}$ Significant at $p<0.01$

Table 4. Topics and Selected Quotes from Students Responding to Open-Ended Questions on Note Taking

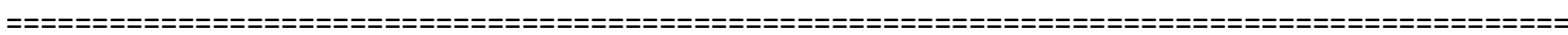

\section{Topic: Evolving Strategies Favoring Longhand Note taking}

"I use a laptop in class, but write out notes by hand right after class."

"I come to class to listen, not to take notes, then I take notes at home."

"I handwrite my notes later."

"I tried writing every word said, then switched to writing down main points, and listening more."

"As the semester went on, I took less notes from the slides and relied more on listening."

"I started writing notes only when deemed necessary."

"Only took notes when slides were lacking in detail."

"I started taking more handwritten notes."

Topic: Alternative Strategies: Still Looking for an Answer

"Still looking for the best note taking strategy that fits me."

"We began taking notes collaboratively, and it helped."

"I took notes on my iPad where I was able to type and also handwrite."

\section{Topic: Class Policy Suggestions Regarding Note taking}

"Ban electronics and print out the slides."

"I have a short attention span and find myself distracted with easy access to my computer and phone."

"Require several lectures to be electronics-free."

"Share notes from the good note takers. Those notes should be for everyone. We are all in this together."

"Assign work study students a job for good note taking."

\section{Topic: Improve Lecture Slides to Facilitate Student Learning}

"Put more material on the slides so we don't have to write so much."

"Highlight points on the slide."

"Emphasize important ideas on the slides with stars and different colors."

"Color-code and bold the notes."

"Put a summary slide up for each lecture."

"Draw more diagrams on the slides."

Topic: Maintaining Laptop Use

"I like using my laptop for filing and finding files later on."

"Taking handwritten notes is hard because I'm worried that I won't be able to get everything that's said."

"I can type faster than I can write."

"I can't write as fast as I can type."

"Although I get distracted, I still prefer my laptop."

"Hard to keep up without a laptop."

"Not enough time to take notes by hand or by laptop."

Questions were: "Do you have any comments about note taking in PRMC 603, or note taking in general?" and "In general, what could faculty, staff, administrators, or even other persons do to promote effective note taking by students? 
Table 5. Longhand Note Takers' Perceptions about Taking Notes and Participating in the Experiment

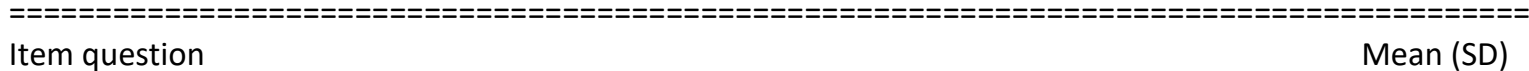

1. As a result of hand-taking notes in PRMC 603, I have already or will begin hand-taking notes in other courses.

2. Taking notes by hand took some getting used to.

3. Even though it might not work for everyone, I would recommend to students that they try taking notes by hand versus using a laptop to do so.

4. Taking notes by hand is probably more suitable for some courses and for some instructors than for others.

5. I have good handwriting speed.

6. Students without good handwriting speed can still be effective longhand note takers.

$4.40(0.97)$

Response scale: 1 = Strongly Disagree; 2 = Disagree; 3 = Slightly disagree; 4 = Slightly agree; 5= Agree; 6 = Strongly Agree.

Table 6. Longhand Note Takers' Comments about Note Taking and Being Enrolled in the Study

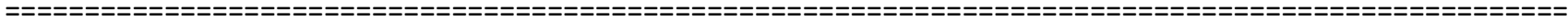
"I think my grade improved because I learned how to better study which is independent of my note taking skills."

"It was fun to take handwritten notes, as it made learning the materials easier at the end."

"I was not as concerned with grammatical errors like if I'm typing. Instead, I spent more time listening and understanding. I worried less."

"Encourage other students to try it. I use different colored pens, and I think that part is very helpful."

"I liked taking them by hand knowing I could go back and listen to lecture recordings. Then, I know when I was missing something."

"Didn't have to think about connectivity, malfunctions, and other problems."

"Very effective. It reduced the total time needed to study for exams and significantly boosted my grades."

"Nice that we didn't HAVE to do it for all lectures."

"What are the results?"

Question = "Do you have any comments about having participated in this note taking study?" 